\title{
Prediction of Ship Motions and Added Resistance in Head Waves Base on Linera Strip Theory
}

\author{
Tran Ngoc Tu, Nguyen Thi Hai Ha, Do Duc Luu
}

\begin{abstract}
Prediction of ship motions and added resistance is an importance step in the ship design phases and considerable researches are related to this subject. It plays a unique role in main seakeeping characteristics such as maximum ship speed in sea waves, voluntary and involuntary speed reduction due to wave forces and added resistance as well as ship safety and ship routing, which affect transportation time, fuel consumption and total cost. The effects of environmental condition on calculation results is analyzed by performing some calculation with different wave parameter of JONSWAP spectra. The calculation results for the DTMB vessel are examined by the comparisons with experimental data carried out at Ship Design and Research Centre's towing tank in Poland, and show good agreement, which demonstrates the ability of the present method to assess seakeeping characteristics at the initial ship design phases. The calculation is performed by using the commercial software MAXSURF.
\end{abstract}

Keywords : ship motion, Strip theory, added ship resistance, pitch motion, heave motion.

\section{INTRODUCTION}

When planning design of new vessels one always needs to have a rational basis for a techno-economic evaluation of alternative designs. This evaluation should include the vessel's operational performance where the seakeeping capability is one of the most importance factors. Study seakeeping provide information about the behaviour of the ship in seaway. The results from such study are motion characteristics and added ship resistance in waves would be used to assess the variant of design in aspect of safety and economy in service, regularity and adequate operation. In recent year, there are three general ways to evaluate ship motions, including: Measurement in full scale ship; model test and numerical methods. All approaches mentioned above have some restrictions. Although, both of the first and the second method are advance in providing high reliability results, but these require highest cost and time. As a result, these methods may not use in the concept design phase. The last one, though, having reliability not as high as the two

Revised Manuscript Received on September 25, 2019

* Correspondence Author

Tran Ngoc Tu, Vietnam Maritime University, Faculty of Ship building, 484 Lach Tray str, Le Chan District, Hai Phong 180000, Vietnam. Email: hant.dt@vimaru.edu.vn

Nguyen Thi Hai Ha, Vietnam Maritime University, Faculty of Ship building, 484 Lach Tray str, Le Chan District, Hai Phong 180000, Vietnam

Do Duc Luu, Vietnam Maritime University, Maritime research institute, 484 Lach Tray str, Le Chan District, Hai Phong 180000, Vietnam

previous ones, its advantage is saving calculation time as well as the expenditure thus it is applying widely in the initial design stage, in which many variants need to be estimated in order to finger out the most optimal one in very limitted time. Depending on the assumption to simplify the fluid equations, there are two different fields for numerical approach in marine hydrodynimics:

- Potential flow theory: Panel method [1], [2], [3] and strip theory [4].

- Reynolds-Averaged Navier-Stock Equation (RANSE) modeling.

In spite of having higher level of accuracy of RANSE than that of Potential flow theory, but the computational time required by Potential flow theory is much lower than the requiring calculation time of RANSE [2], [5]. For that reason, it is more suitable to use Potential flow theory in the initial design period because in this period, the calculation time of finding the most optimal variant among a numerous variants is very short. This study presents the theoretical background and application of the linear strip theory for ship seakeeping calculation by using commercial software MAXSURF [11]-[14].

\section{THEORETICAL BACKGROUND OF STRIP THEORY}

\section{A. Strip theory method}

Strip theory is a frequency-domain method. This mean that the proplem is formulate as a funtion of frequency, so it is simpler and less computationally intensive than time domain approach. The values of two-dimensional hydromechanics coefficients will be integrated over the ship length numerically. The ship is considered to be a rigid body [5], [6]. The procedure of this method is showed in fig. 2 .

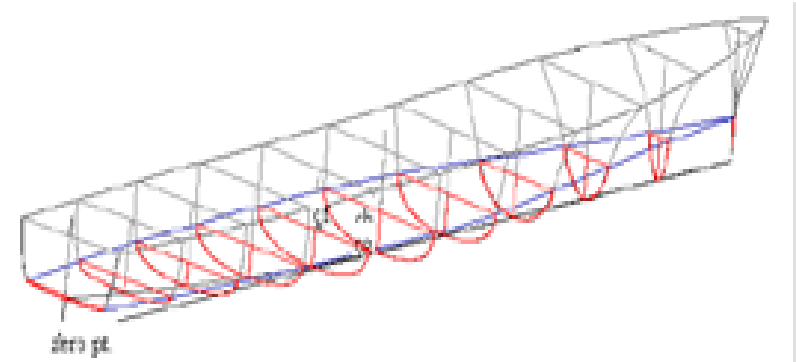

Figure.1. Strip theory representation by sross sections 


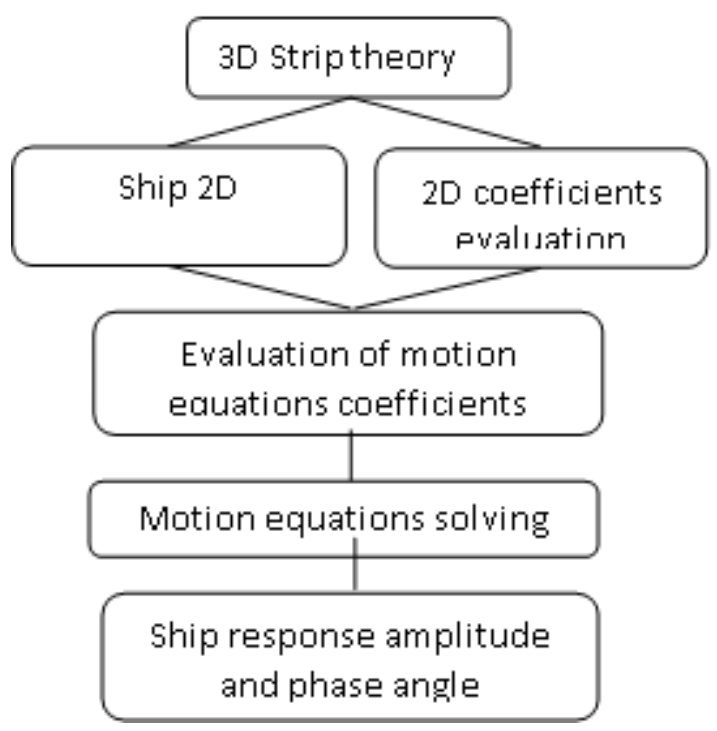

Figure 2: Strip theory procedure

The details of basic background of strip theory is provided in detail in reference [4],[5], [7], thereby in the content of this article the authors will no longer concern about this issue.

\section{B. Assumptions of strip theory}

Recently, the strip theory has been widely used for seakeeping analysis [8].

\section{NUMERICAL SIMULATIONS}

\section{A. Reference vessel}

The vessel under study in this paper is a US Navy Combatant DTMB, shown in Figure 3, with characteristics of the ship are given in table 1 . The main reason for using this hull is that the hull geometry is a public domain [9], and extensive database of seakeeping test exists at different Froude numbers and sea state, that were carried out by Ship Design and Research Centre CTO S.A.

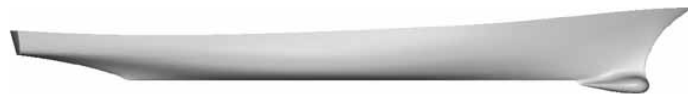

Figure 3: Geometry of DTMB

Table 1. Main particulars of the DTMB

\begin{tabular}{|c|c|c|}
\hline \multicolumn{2}{|c|}{ Description ship parameter } & value \\
\hline $\begin{array}{c}\text { Length between } \\
\text { perpendiculars }\end{array}$ & $L_{P P}(m)$ & 142.0 \\
\hline Length at water level & $L_{W L}(m)$ & 142.0 \\
\hline Breadth & $B(m)$ & 18.9 \\
\hline Draft & $T(m)$ & 6.16 \\
\hline Volume & $\square\left(m^{3}\right)$ & 8425 \\
\hline metacentric height & $G M(m)$ & 1.95 \\
\hline Gyration & $i x x / B$ & 0.37 \\
\cline { 2 - 3 } & $i z z / L_{P P}$ & 0.25 \\
\hline
\end{tabular}

\section{B. Input data for ship motion calculation}

The commercial software MAXSURF was used for the computation. For ship motion calculation, it is necessary to require the following input data:
- 3D ship geometry;

- Vessel conditions: Vessel draft and trim; Vertical centre gravity; vessel hydrostatics (these parameters can be defined automatically by Maxsurf base on the hull geometry);

- Ship speed;

- Environmental conditions: wave spectrum (spectrum type, characteristic height, period...).

\section{Test cases}

Computations were performed for the following conditions: - Vessel condition: $\operatorname{draft} \mathrm{T}=6.16 \mathrm{~m} ; \mathrm{VCG}=7.55 \mathrm{~m}$; Trim $=$ 0 .

- Vessel speed: at three speed 18, 24 and 30 knots for calculating added ship resistance; and 8, 13 and 18 knots for calculating pitch, heave motion

- Environmental condition:

+ The following parameters were considered in the simulations added ship resistance: JONSWAP spectrum, hs $=2.41$ and $4.25 \mathrm{~m}$; modal periods $\mathrm{Tp}=9.24 \mathrm{~s}$ and $9.8 \mathrm{~s}$ in head sea condition.

+ The following parameters were considered in the simulations heave and pitch motion: JONSWAP spectrum, hs $=2.16,2.07$ and $2.26 \mathrm{~m}$; average periods is corresponding to $\mathrm{T} 01=8.111 \mathrm{~s}, 8.033 \mathrm{~s}$ and 8.188 in head sea condition.

\section{Computational setup}

\section{Measure hull}

The mapped sections are used to compute the section hydrodynamic properties. For DTMB ship, 18 numbers of mapped sections are used. Typical mappings of DTMB ship are shown in fig. 4.

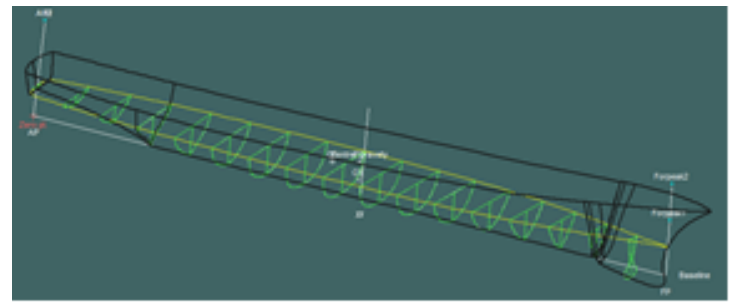

Figure 4. The mapped sections of DTMB

\section{Setting mass distribution}

To calculate ship motion requires the pitch and roll inertias of the vessel. These are input as gyradii in percent of overall length and beam respectively. For DTMB vessel the roll gyradius ixx/B $=0.37$, pitch gyradius izz/LPP $=0.25$. The vertical centre of gravity $\mathrm{VCG}=7.55$.

\section{Setting dapping factor}

The roll response is calculated based on the vessel's hydrostatic properties. For DTMB vessel the Non-dimensional damping factors are setup at 0.075 for Roll (total) and zero for Heave/Pitch (additional).

\section{Choice analysis method}

No Transom terms, Salvesen method and Head seas approximation were applied for analysis method for calculating seakeeping of DTMB vessel. 


\section{RESULT AND DISCUSSION}

Computational results for added ship resistance, heave and pitch motion in head wave at different ship speed and sea state are shown in table 2, 3, 4 and fig.5, 6 and 7.

Table 2. Added ship resistance in head wave at different ship speed and sea state

\begin{tabular}{|c|c|c|c|c|c|c|}
\hline \multirow{2}{*}{ STT } & \multirow{2}{*}{$\begin{array}{c}\text { Ship speed, } \\
{[\mathrm{knots}]}\end{array}$} & \multicolumn{2}{|c|}{ Wave parameter } & \multicolumn{2}{|c|}{$\mathrm{R}_{\mathrm{Aw}},[\mathrm{kN}]$} & \multirow{2}{*}{$\begin{array}{c}\text { Relative error, } \\
{[\%]}\end{array}$} \\
\cline { 3 - 6 } & $\mathrm{h}_{\mathrm{s}},[\mathrm{m}]$ & $\mathrm{T}_{\mathrm{p}},[\mathrm{m}]$ & Simulation & Exp. [10] & \\
\hline 1 & 18.0 & 4.25 & 9.236 & 252.00 & 285.40 & $11.70 \%$ \\
\hline 2 & 18.0 & 2.41 & 9.775 & 93.57 & 105.00 & $10.89 \%$ \\
\hline 3 & 24.0 & 2.41 & 9.775 & 81.00 & 83.41 & $2.89 \%$ \\
\hline 4 & 30.0 & 2.41 & 9.775 & 67.90 & 63.70 & $-6.60 \%$ \\
\hline
\end{tabular}

Table 3. Pitch motion in head wave at different ship speed and sea state

\begin{tabular}{|c|c|c|c|c|c|c|c|c|c|}
\hline \multirow{2}{*}{ STT } & \multirow{2}{*}{$\begin{array}{c}\text { Ship } \\
\text { speed, } \\
{[\text { knots] }}\end{array}$} & \multicolumn{2}{|c|}{ Wave parameter } & \multicolumn{2}{|c|}{$\mathrm{A}_{1 / 3 \_\mathrm{P}}[\mathrm{deg}]$} & \multirow{2}{*}{$\begin{array}{c}\text { Relative } \\
\text { error, [\%] }\end{array}$} & \multicolumn{2}{|c|}{$\mathrm{T}_{01 \_\mathrm{P}}[\mathrm{s}]$} & \multirow{2}{*}{$\begin{array}{c}\text { Relative } \\
\text { error, [\%] }\end{array}$} \\
\hline & & $\mathrm{h}_{\mathrm{s}},[\mathrm{m}]$ & $\mathrm{T}_{01},[\mathrm{~m}]$ & Simulation & Exp. [10] & & Simulation & Exp. [10] & \\
\hline 1 & 8 & 2.16 & 8.111 & 1.37 & 1.28 & $-7.0 \%$ & 7.701 & 7.956 & $3.2 \%$ \\
\hline 2 & 13 & 2.07 & 8.033 & 1.36 & 1.385 & $1.8 \%$ & 6.828 & 7.078 & $3.5 \%$ \\
\hline 3 & 18 & 2.26 & 8.188 & 1.51 & 1.375 & $-9.8 \%$ & 6.312 & 6.509 & $3.0 \%$ \\
\hline
\end{tabular}

Table 4. Heave motion in head wave at different ship speed and sea state

\begin{tabular}{|c|c|c|c|c|c|c|c|c|c|}
\hline \multirow{2}{*}{ STT } & \multirow{2}{*}{$\begin{array}{c}\text { Ship } \\
\text { speed, } \\
\text { [knots] }\end{array}$} & \multicolumn{2}{|c|}{ Wave parameter } & \multicolumn{2}{|c|}{$\mathrm{A}_{1 / 3 \_\mathrm{H}}[\mathrm{m}]$} & \multirow{2}{*}{$\begin{array}{l}\text { Relative } \\
\text { error, [\%] }\end{array}$} & \multicolumn{2}{|c|}{$\mathrm{T}_{01 \_\mathrm{H}}[\mathrm{s}]$} & \multirow{2}{*}{$\begin{array}{c}\text { Relative } \\
\text { error, [\%] }\end{array}$} \\
\hline & & $\mathrm{h}_{\mathrm{s}},[\mathrm{m}]$ & $\mathrm{T}_{01},[\mathrm{~m}]$ & Simulation & Exp. [10] & & Simulation & Exp. [10] & \\
\hline 1 & 8 & 2.16 & 8.111 & 0.436 & 0.402 & $-8.5 \%$ & 8.002 & 8.369 & $4.4 \%$ \\
\hline 2 & 13 & 2.07 & 8.033 & 0.518 & 0.508 & $-2.0 \%$ & 7.061 & 7.310 & $3.4 \%$ \\
\hline 3 & 18 & 2.26 & 8.188 & 0.721 & 0.671 & $-7.5 \%$ & 6.495 & 6.664 & $2.5 \%$ \\
\hline
\end{tabular}

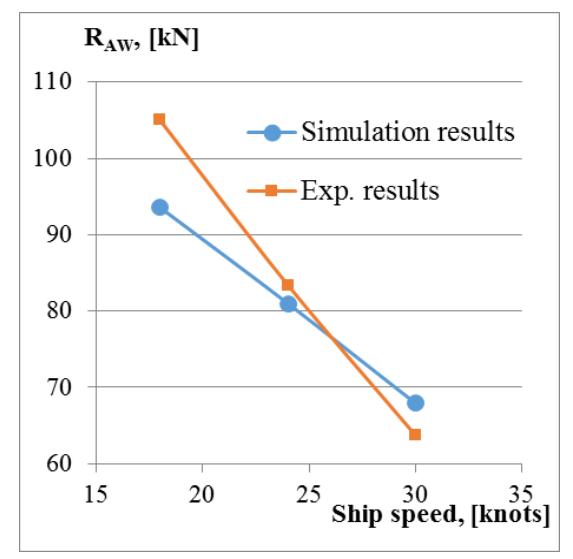

Figure 6: Relationship between added ship resistance and ship speed in head wave at $\mathrm{hs}=2.41$ and $\mathrm{Tp}=9.775$

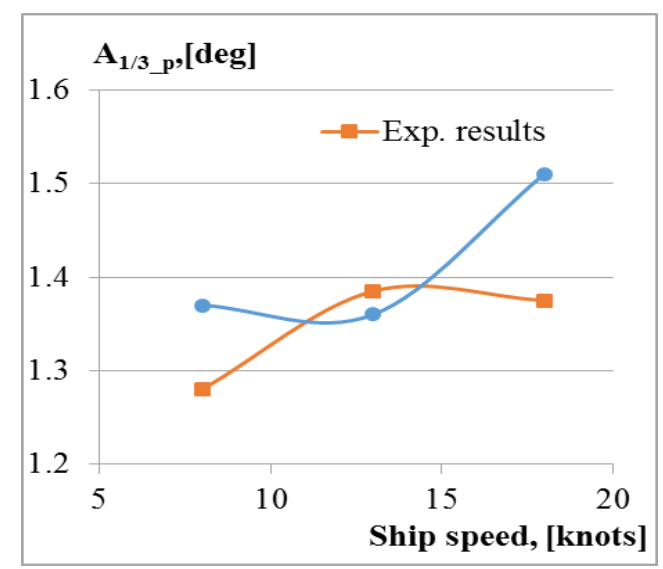

Figure 7: Relationship between significant amplitude of pitch motion and ship speed in head wave 


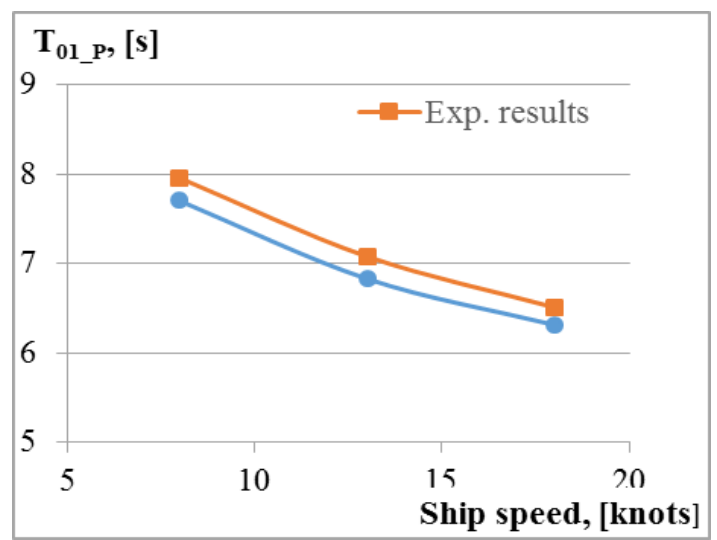

Figure 8. Relationship between average period of pitch motion and ship speed in head wave

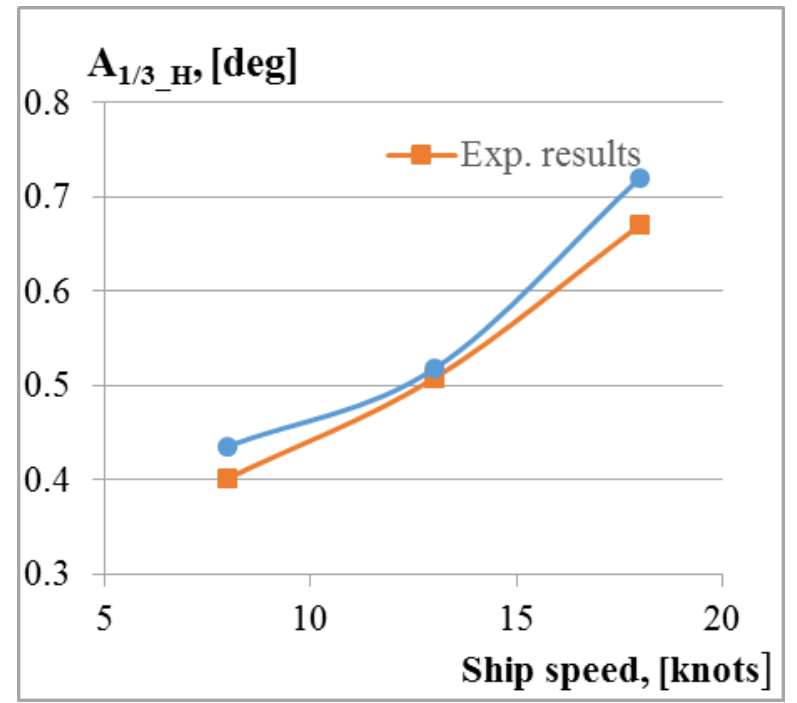

Figure 9. Relationship between significant amplitude of heave motion and ship speed in head wave

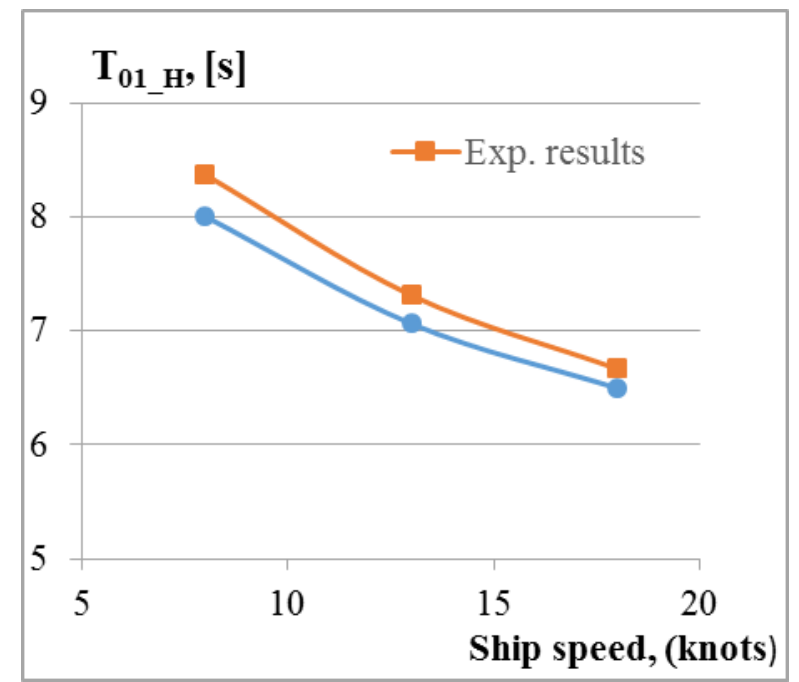

Figure 10. Relationship between average period of heave motion and ship speed in head wave

By making comparison between the obtained results and those from experiment in towing tank (was translated into full-scale), the bellowed comments are provided:

- The tendency of changes of added ship resistance, pitch and heave motion at different speed are similar to experiment results. This is very important in application of
Strip theory in study ship motion in initial ship design phases. Besides, the calculation only shows that the tendency in increase of added ship resistance varies strongly with ship speed.

- The difference in added ship resistance between calculation results and those of experiment is ranged from 7 to $12 \%$ depending on ship speed and sea state. This discrepancy can be acceptable in the initial design phase.

The difference in pitch and heave motion between calculation result and that of experiment is lower than $9 \%$ for significant amplitude and lower than 5\% for average period.

\section{CONCLUSION}

In this paper, the authors have considered and solved the following issues:

- Analysis and chose the suitable method to estimate ship motion in the initial design stage;

- Provide the basic background and the assumptions of strip theory in calculating ship motion.

Present the results of calculating ship motion for DTMB vessel by using Strip theory in commercial software MAXSURF. Calculation result agrees well with the experiment data. This is very important in application of Strip theory in study ship motion in initial ship design phases.

\section{ACKNOWLEDGMENT}

The authors are grateful to the Vietnam Maritime University and CTO for providing necessary research facilities during current research work.

\begin{tabular}{|c|c|}
\hline & NOMENCLATURE \\
\hline$B[m]:$ & Ship breadth \\
\hline$i x x:$ & Moment of inertia for roll \\
\hline$i z z:$ & Moment of inertia for pitch \\
\hline$G M$ & Metacentric height \\
\hline$[m]:$ & \\
\hline$h_{s}[m]:$ & Significant wave height \\
\hline$L_{P P}$ & Length between perpendiculars \\
\hline$[m]:$ & \\
\hline$L_{W L}$ & Length at water level \\
\hline$[m]:$ & \\
\hline$R_{A W}$ & Added ship resistance due to wave \\
\hline$[K N]:$ & \\
\hline$T[m]:$ & Ship draft \\
\hline$T p[s]:$ & Wave modal period \\
\hline$T_{01 \_P}$ & Average period of pitch motion \\
\hline$[s]:$ & \\
\hline$T_{01 \_H}$ & Average period of heave motion \\
\hline$[s]:$ & \\
\hline$A_{-1 / 3}$ & Significant amplitude of ship \\
\hline$[m]:$ & motions (pitching, heaving) \\
\hline$\left[m^{3}\right]:$ & Ship volume displacement \\
\hline
\end{tabular}




\section{REFERENCES}

1. G. O. Young, "Synthetic structure of industrial plastics (Book style with 1. Newman, J.N. Panel methods in marine hydrodynamics. in Proc. Conf. Eleventh Australasian Fluid Mechanics-1992. 1992.

2. Kring, D.C., Time domain ship motions by a three-dimensional Rankine panel method. 1994, Massachusetts Institute of Technology.

3. Kim, K.-H. and Y. Kim, Numerical study on added resistance of ships by using a time-domain Rankine panel method. Ocean Engineering, 2011. 38(13): p.1357-1367.

4. Journée, J., Quick strip theory calculations in ship design. Newcastle upon Tyne: sn, 1992.

5. BASO, S., et al., New Strip Theory Approach to Ship Motions Prediction.

6. Journée, J.M. and W. Massie, Offshore hydrodynamics. Delft University of Technology, 2001. 4: p. 38.

7. MAXSURF Motions Program \& User Manual, Bentley Systems, Incorporated, 2016

8. MAXSURF Motions Program \& User Manual 2016 Bentley Systems, Incorporated.

9. Chrismianto, D. and D.-J. Kim, Parametric bulbous bow design using the cubic Bezier curve and curve-plane intersection method for the minimization of ship resistance in CFD. Journal of Marine Science and Technology, 2014. 19(4): p. 479-492.

10. Seakeeping test report for DTMB vessel. CTO, Poland 2017.

11. Naderi R. Solving a nonlinear Singular Cauchy Problem of EulerPoisson-Darboux Equation through Homotopy Perturbation Method. Medbiotech Journal. 2019;03(02):29-34

12. Mirabbasi, D., parvin, M., \& javid, H. (2015). A Comparison of Several Approaches to Load Frequency Control of Multi Area Hydro-Thermal System. UCT Journal of Research in Science, Engineering and Technology, 3(4), 24-30.

13. Mnunguli, J. P., \& Kisangiri, M. (2018). Evidence based Practices for Drug Abuse Information Management and Awareness Approaches. Journal of Information Systems Engineering \& Management, 3(4), 31.

14. Osman, S., Che Yang, C. N. A., Abu, M. S., Ismail, N., Jambari, H., \& Kumar, J. A. (2018). Enhancing Students' Mathematical Problem-Solving Skills through Bar Model Visualisation Technique. International Electronic Journal of Mathematics Education, 13(3), 273-279. https://doi.org/10.12973/iejme/3919 